FACTA UNIVERSITATIS

Series: Automatic Control and Robotics Vol. 19, N 1, 2020, pp. 39 - 58

https://doi.org/10.22190/FUACR2001039S

\title{
LINE-START SYNCHRONOUS MOTOR A VIABLE ALTERNATIVE TO ASYNCHRONOUS MOTOR
}

\author{
UDC (621.314:621.313.13)
}

\section{Vasilija Šarac}

University Goce Delcev, Faculty of Electrical Engineering, Republic of North Macedonia

\begin{abstract}
Advancements in power electronics that contributed to the easier starting of synchronous permanent magnet motors have increased the significance of this type of motors, widely known as not-self-starting motors. However, power electronics, which is necessary, for the starting of the synchronous motor contributed also to the complexity of this type of motor drives as well as to increased operational and maintenance cost. The line-start synchronous motors have gained the popularity during recent years as a viable alternative to asynchronous motors due to an easy line starting similar to the asynchronous motors and good operational parameters such as high efficiency and power factor. The paper presents the design of a line-start synchronous motor, derived from an asynchronous motor, by redesigning the rotor with flux barriers and permanent magnets. The computer models for calculating parameters and operating characteristics of both motors were modeled and the accuracy of the obtained results was verified by comparison with experimental data. Motor transient characteristics of speed, current and torque for the line starting of the both motors, when they were fed with the voltage from the network, were determined as well. The obtained transient characteristics of both motors were compared and adequate conclusions regarding line starting of both motors were derived. The newly derived synchronous motor for line starting has good operational characteristics such as increased efficiency, power factor and starting torque compared with the respected parameters of the asynchronous motor, good transient and steady-state operating characteristics and good dynamic response at sudden load change.
\end{abstract}

Key words: line-start synchronous motor, transient characteristics, FEM models, efficiency

\section{INTRODUCTION}

Climate changes and the necessity of the reduction of $\mathrm{CO}_{2}$ emission has stipulated introduction of various standards, which limit the air pollution and enforce the electricity

Received May 24, 2020

Corresponding author: Vasilija J. Sarac

Faculty of Electrical Engineering, Krste Misirkov 10-A, 2000 Štip, Republic of North Macedonia

E-mail: vasilija.sarac@ugd.edu.mk 
savings. The European regulations for energy efficient motors are covered by IEC 60034$30-1$, which defines the efficiency levels of the motors as IE1 standard efficiency, IE2 high efficiency, IE3 premium efficiency and IE4 super premium efficiency. IE3 efficiency levels have to be reached for motors from 0.75 to $375 \mathrm{~kW}$, by January 1,2017 or IE2 in combination with an adjustable speed drive. From July 2021 the level of requirement will moreover increase, as three-phase motors with a rated output between $0.75 \mathrm{~kW}$ and equal or below $1000 \mathrm{~kW}$ must reach IE3 efficiency level by July 2021. The motor manufacturers and industry are facing the challenge to design and use motors that are more efficient. The prime moving force in most of the industries that utilize motors with constant speed is the three phase squirrel cage motor (AM). It is well- known as a robust and reliable motor, which requires little maintenance. However, this type of motors can reach premium efficiency levels (IE3) and encounters a number of design issues when super premium efficiency levels (IE4) should be reached. Permanent magnet synchronous motors are known as a viable alternative to asynchronous squirrel cage motors as they have a higher efficiency and power factor compared with the asynchronous motors. Besides being more expensive than threephase squirrel cage motors, synchronous motors require an inverter for motor starting i.e. putting into operation. This makes the synchronous motor an even more expensive alternative to the asynchronous motors. The line-start synchronous permanent magnet motors (LSSPMM), designed as a hybrid of asynchronous squirrel cage motor and synchronous motor, can achieve super premium efficiency levels (IE4). As the name indicates, they are capable for line starting when they are plugged into the network voltage. This is due to the existence of squirrel cage winding on the rotor (like at asynchronous motors) which enables asynchronous starting of the motor. In addition, flux barriers with magnets are placed in the rotor. The permanent magnets and flux barriers contribute to torque component in the steady-state synchronous operation. The torque from the magnets is known as the breaking torque as it opposes the cage torque. Unlike asynchronous motor, LSSPMM operates with constant synchronous speed within the complete range of the loads. As it operates with constant synchronous speed, no current is induced in the rotor winding, once the motor reaches the synchronous speed. Consequently, the copper losses in rotor winding are nullified. The design of the LSSPMM, influence of the various motor parameters like the number of the stator winding turns, rotor configuration or voltage unbalance, on the operating characteristics of the motor have been the subject of investigation during recent years [1]-[10]. The other authors focus on the cogging torque reduction and improvement of the motor performance during starting and at the steady-state operation [11]-[14]. The single-phase line-start synchronous motors have also attracted the attention of the researchers and motor designers as they can be widely used in various household appliances [15]-[16]. The research on the field of the line-start motors is not limited to the synchronous motors with permanent magnets. The capabilities of hysteresis and reluctance motors for the direct line starting are investigated as well [17]-[18]. Faults that can occur during operation of line-start synchronous permanent magnet motors are subject to the mathematical modeling, simulation and analysis [19]-[21]. Optimization algorithms have gained the popularity during the last decade and they are widely applied at the design of the motors as they allow obtaining the most favorable motor design regarding predefined motor parameters such as efficiency or torque [22]-[23]. However, very few papers address the comparison of steady state and dynamic characteristics of the line-start synchronous motors and the asynchronous motors. In this paper, the line-start synchronous 
motor is derived from the asynchronous motor by reconfiguring the rotor. Moreover, the synchronous motor is designed to have the same output power as the asynchronous motor and same mounting dimensions, achieved with minimal consumption of permanent magnet material and minimal intervention in motor design and dimensions. Both motors are modeled in the Ansys Electronic Desktop software and the parameters and the steady-state characteristics of both motors are obtained. The Finite Elements Method for calculating the magnetic flux density distribution further extends the analysis of design of the newly derived synchronous motor. The Software Simplorer is used for obtaining transient characteristics of both motors when they are fed by the symmetrical voltage supply from the network. The dynamics of the motors is analyzed at no load, with a step load coupled to the motor shaft and at acceleration with the rated load. From the obtained results, the overall operation of the line-start synchronous motor is superior over the operation of an asynchronous motor. However, its limitations are related to the limited starting capability due to the breaking torque from the permanent magnets. Therefore, LSSPMM are intended for driving lowinertia loads and they are not suitable for all applications. Thus, a further research on finding the optimal rotor design with respect to the motor steady state and dynamic operation should improve the overall operation of this type of the motor.

\section{MOTOR MODELS}

\subsection{Analytical models of the motors for computer modeling}

The key step in each motor analysis is to define accurately the motor model that is used for computer modeling. The starting point in the analysis is three-phase asynchronous motor, type 2AZ 155-4, product of the company Rade Končar (AM). The data of this motor including the nameplate data are presented in Table 1 [24]. The asynchronous motor model is modeled in Ansys Electronic Desktop, or more precisely, in the software module that allows obtaining the motor parameters and steady-state characteristics. This model will be referred to as an analytical model of the asynchronous motor (AMAM). A more detailed presentation of this model can be found in [24]. The accuracy of this model is verified by comparing the output parameters and characteristics of AMAM with the data from the motor producer and measurements in the faculty's laboratory. This comparison is presented in Table 2. In order to obtain a valid computer model for the analytical calculation of motor parameters and steady state characteristics, all motor dimensions and properties of materials must be input into the computer model. Once it was determined that the computer model of the asynchronous motor for the analytical calculation of motor parameters and characteristics was sufficiently accurate, the motor was redesigned into the line-start synchronous permanent magnet motor by redesigning the rotor and adding the flux barriers and magnets inside the barriers. All other dimensions of the motor were not changed i.e. the same mounting frame was retained in both cases. The derivation of the model of line-start permanent synchronous motor from the asynchronous squirrel cage motor was done with one constraint, the output mechanical power of both motors should be the same. This model will be referred to as the analytical model of the synchronous motor or AMSM. The crosssection of both models is presented in Fig. 1. 


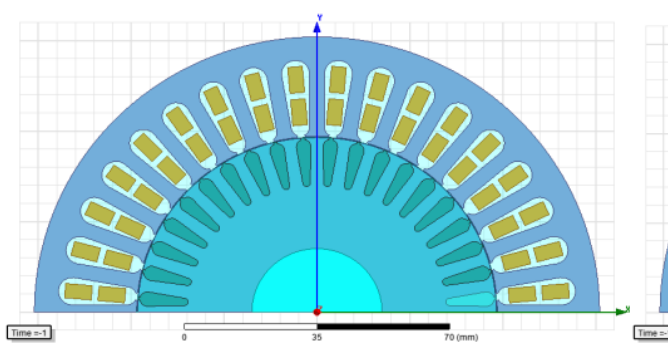

a) AMAM

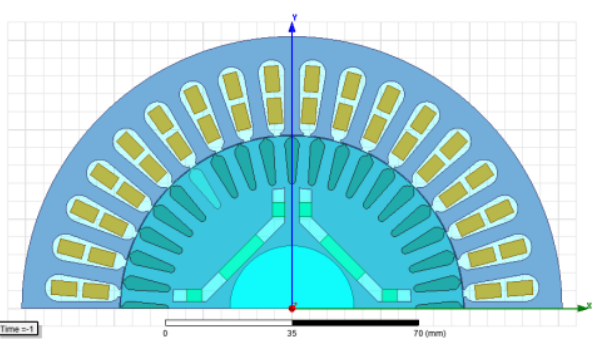

b) AMSM

Fig. 1 Cross-section of motors

Table 1 Data of asynchronous motor

Table 2 Comparison of data of AMAM

\begin{tabular}{ll}
\hline Parameter & Value \\
\hline nominal power & $\mathrm{P}=2.2 \mathrm{~kW}$ \\
number of poles & $2 \mathrm{p}=4$ \\
nominal voltage $\Delta / \mathrm{Y}$ & $220 / 380 \mathrm{~V}$ \\
nominal current $\Delta / \mathrm{Y}$ & $8.7 / 5 \mathrm{~A}$ \\
power factor & $\cos \varphi=0.81$ \\
nominal speed & $1410 \mathrm{rpm}$ \\
number of stator slots & $\mathrm{Z}_{1}=36$ \\
number of rotor slots & $\mathrm{Z}_{2}=40$ \\
stator winding & $\mathrm{R}_{1}=2.76 \Omega$ \\
resistance per phase & \\
stator outer diameter & $\mathrm{D}_{\mathrm{sa}}=152 \mathrm{~mm}$ \\
stator inner diameter & $\mathrm{D}_{\mathrm{si}}=97 \mathrm{~mm}$ \\
radial air gap length & $\mathrm{g}=0.6 \mathrm{~mm}_{\text {stack length }}$ \\
nominal frequency & $\mathrm{f}=50 \mathrm{~Hz}$ \\
\hline
\end{tabular}

\begin{tabular}{lrrr}
\hline Parameter & $\begin{array}{c}\text { Analyt } \\
\text { model }\end{array}$ & Exp. & Producer \\
\hline phase current (A) & 5.24 & 4.88 & 5 \\
no-load phase current (A) & 2.89 & 2.36 & 2.4 \\
no-load input power (W) & 135 & 196 & 170 \\
locked-rotor phase & 22.1 & 22 & 21 \\
current (A) & & & \\
locked rotor torque ratio & 2.4 & $/$ & 2.2 \\
nominal output power & 2.19 & 1.94 & 2.2 \\
(kW) & & & \\
nominal power factor (/) & 0.8 & 0.78 & 0.81 \\
efficiency (\%) & 79.4 & 77.5 & 81 \\
rated speed (rpm) & 1356 & 1410 & 1410 \\
\hline
\end{tabular}

Table 3 presents the stator and rotor winding parameters of the both motors. These winding parameters are defined during the modeling process of the computer models for calculating motor parameters and steady state characteristics (analytical model). The demagnetization of the magnets is also taken into consideration during the motor design. The demagnetization fault is caused due to magnetic fields in the opposite direction that occur as a result of current passing through stator windings. The maximum permitted steady-state current before the reverse field exceeds $\mathrm{H}_{\mathrm{d}}$, the field intensity vector on the demagnetization curve where magnetic vector collapses, is calculated from:

$$
I_{d g m r m}=\frac{p \pi}{6 \mu_{0}\left(K_{W} N_{c}\right)}\left(B_{r} h_{m}-B_{d}\left(g+h_{m}\right)\right)
$$

$\mathrm{K}_{\mathrm{w}}$ is the winding coefficient, $\mathrm{N}_{\mathrm{c}}$-conductors per slot, $\mathrm{B}_{\mathrm{r}}$ is the residual flux density in Tesla and $g$ is the air gap length in meters, $h_{m}$ is the magnet thickness in meters. This maximum permitted steady-state current must be greater than the rated one to prevent the demagnetization [25]. 
Table 3 Stator and rotor winding parameters

\begin{tabular}{lc}
\hline \multicolumn{1}{c}{ Parameter } & Value \\
\hline \multicolumn{1}{c}{ AMAM \& AMSM } \\
\hline winding layers & 2 \\
parallel branches & 2 \\
conductor per slot & $\mathrm{N}_{\mathrm{c}=97}$ \\
coil pitch & 7 \\
rotor bar conductor & Cast aluminium \\
rotor end ring width (mm) & 8 \\
rotor end ring height (mm) & 19 \\
\hline \multicolumn{1}{c}{ AMSM } & 3.4 \\
\hline magnet thickness (mm) & 23 \\
magnet width (mm) & 67.4 \\
D1 (mm) & 1 \\
O2 (mm) & 4 \\
Rib (mm) &
\end{tabular}

The dimensions of the flux barriers and magnets (Fig. 2), which are added to the rotor of the asynchronous motor in order to obtain the line-start synchronous permanent magnet motor, are chosen on the way that allows the same output power in both motors. This makes the comparison of operating parameters and characteristics of both motors comparable and comprehensible. The dimensions of the flux barriers are presented in Table 3 as well.

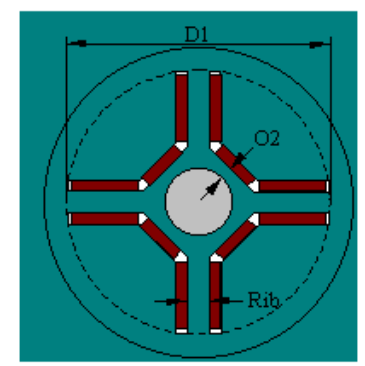

Fig. 2 Flux barriers with magnets

Both models (AMAM and AMSM) have the same stator winding. The only difference is the wire diameter, which in case of AMSM is increased from $0.7 \mathrm{~mm}$ at the asynchronous motor to $0.9 \mathrm{~mm}$ at the synchronous motor. The increase of wire diameter raises the question of available space in stator slots. The limited slot fill factor of the stator winding is $75 \%$. In case of the synchronous motor this constraint is satisfied in spite of the increase of wire diameter, as the slot fill factor is $69.9 \%$. The asynchronous motor with the wire diameter of $0.7 \mathrm{~mm}$ has the slot fill factor of $60 \%$. The principle layout of the stator winding of the synchronous motor is presented in Fig. 3. The rotor winding is the same for both motors, squirrel cage type, made of aluminum, with dimensions presented in Table 2. Another important aspect in defining the models are the properties of the steel laminations i.e. the characteristic of magnetization of the ferromagnetic material. The magnetic flux density B as a function of the magnetic field $\mathrm{H}$ for the used magnetic material in the core of the both motors is presented in Fig. 4. 


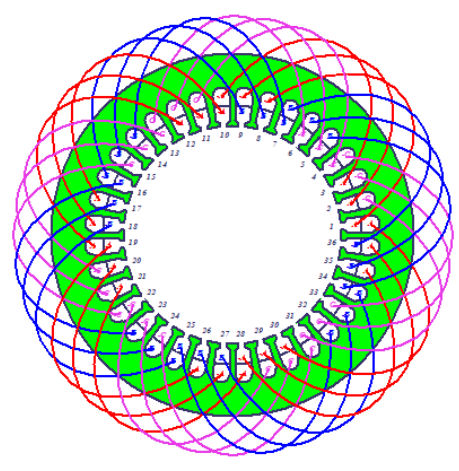

Fig. 3 Winding layout

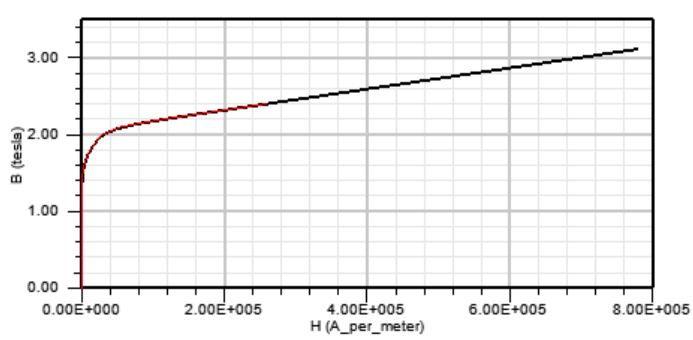

Fig. 4 Charactersitcs of magnetization of core

Dimensions of the stator and the rotor laminations, motor outer dimensions are obtained from the motor producer. Motors are modeled on the base of the exact dimensions from the motor producer. This provides the base for comparison of the obtained results from the analytical model of the asynchronous motor with producer data and provides a base for further modification of the asynchronous motor in the line-start synchronous motor. When modeling the line-start synchronous motor the objective is to maintain the same output power $\mathrm{P}_{2}$ as it is in the asynchronous motor i.e. $2.2 \mathrm{~kW}$. This should be achieved with minimum intervention in motor design i.e. minimum modifications in the asynchronous motor and with minimal consumption of the permanent magnet material. So the model of the line-start synchronous motor is obtained by adding flux barriers and permanent magnet material inside them. By varying the magnet thickness and magnet width, various motor models are obtained but they have different operating characteristics, sometimes very far from the operating characteristics of the asynchronous motor. The model that provides the same output power $\mathrm{P}_{2}$ of the synchronous motor as in the asynchronous motor with minimum net weight of permanent magnet material is considered as the best solution for the line-start synchronous motor. Both motor models (asynchronous and synchronous), after they are solved in the Ansys Electronic Desktop module for analytical calculation of motors, as an output give the motor parameters and steady-state operating characteristics. They will be presented in the next section.

\subsection{Numerical models}

The numerical techniques, i.e. Finite Elements Method (FEM) have become a regular part of motor design procedure as they allow accurate solving of Maxwell's differential equations i.e. obtaining the magnetic flux density $\mathbf{B}$ in each part of the machine crosssection [26]-[28]. The flux density in motor cross section determines the motor core losses. They are constant losses for each operating regime of the motor, i.e. they are not load dependent. The motors are modeled by dividing their cross-section into numerous elements i.e. creating the mesh of finite elements (Fig. 5). The magnetic vector potential $\mathbf{A}$, i.e. magnetic flux density $\mathbf{B}$ are calculated in each point of the motor cross-section, after models are solved in the Ansys Electronic Desktop model for numerical modeling. The obtained results from these models will be presented in the next section. 


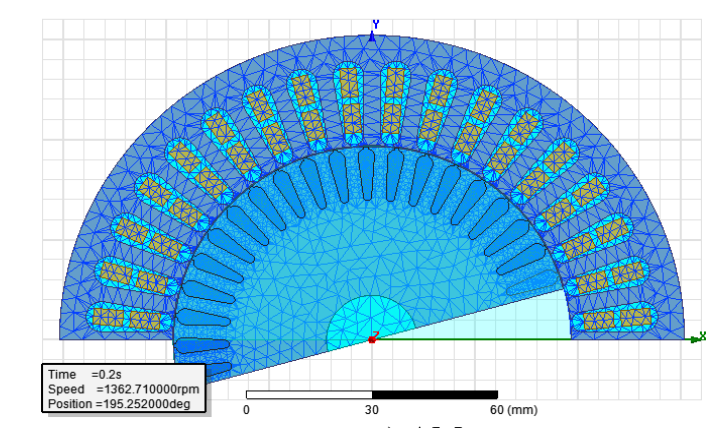

a) $\mathrm{AM}$

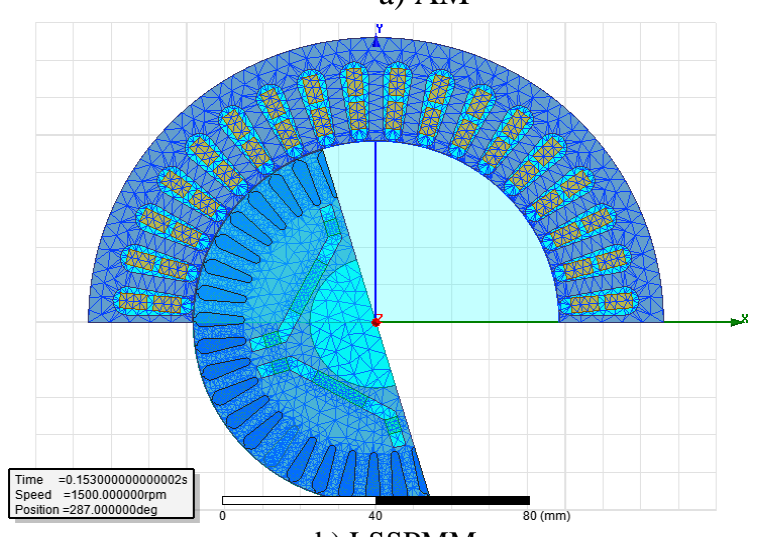

b) LSSPMM

Fig. 5 Numerical models of motors

\subsection{Models for obtaining dynamic characteristics}

The main obstacle in replacing the asynchronous motors with the synchronous is the ability of the latter for line starting and their dynamic behavior at sudden changes of the load. Therefore, it is understandable that modeling of the dynamic characteristics of the motors is the integral part of their analysis. Both motors are modeled in Simplorer, the module of the software Ansys Electronic Desktop that allows obtaining the transient characteristics of the motors at various operating regimes (Fig. 6). Both motors are fed with network voltage i.e. symmetrical three-phase voltage. After transient models are solved, the dynamic characteristics of torque, speed and stator current at step load and for acceleration with rated load are obtained. They allow motor starting and dynamic behavior to be analyzed. Obtaining the transient characteristics of electrical machines is based on Parker transformation. A more detailed representation of the mathematical model can be found in [29]-[30].The dynamic characteristics are also presented in the next section. The obtained results from this model will provide a comparison with the data from the analytical model and will verify the accuracy of both models. 


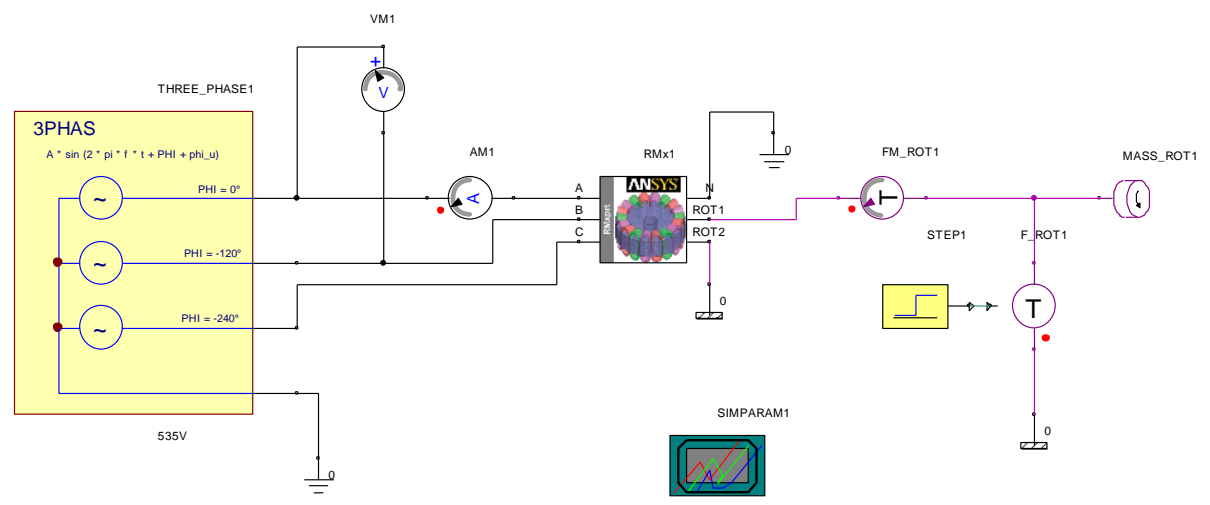

Fig. 6 Modeling dynamic characteristics of the motor

\section{RESULTS}

\subsection{Analytical model}

Analytical models of the motor that are solved in the module of Ansys software for analytical modeling allow calculating parameters and operating characteristics of the motors. The comparison of parameters of both motors is presented in Table 4. The comparison of characteristics of both motors is presented in Table 5. In addition, three operating regimes are compared: no-load, rated load and locked rotor. The comparison and derivation of motor models is done taking into account that in both motor types (models) the output power should remain unchanged. Therefore, in Table 5, both motor models have the same output power $\left(\mathrm{P}_{2}\right)$ of $2.2 \mathrm{~kW}$. The construction and the design of LSSPMM was done on the way that the output power should remain the same as in the asynchronous motor while all other operating characteristics obtained from LSSPMM are compared with the characteristics of the asynchronous motor and the improvements and drawbacks of LSSPMM are observed.

Table 4 Parameters of motors

\begin{tabular}{lcc}
\hline Parameter & AMAM & AMSM \\
\hline phase stator winding resistance at $75^{\circ} \mathrm{C}(\Omega)$ & 3.55 & 1.95 \\
wire diameter of stator winding $(\mathrm{mm})$ & 0.72 & 0.91 \\
slot fill factor $(\%)$ & 60.2 & 69.9 \\
limited slot fill factor $(\%)$ & 75 & 75 \\
stator leakage reactance $(\Omega)$ & 3.7 & 2.98 \\
D-Axis Reactance $(\Omega):$ & $/$ & 28.8 \\
Q-Axis Reactance $(\Omega):$ & $/$ & 167.5 \\
\hline
\end{tabular}

Fig. 7 presents the efficiency for wide range of operating modes, defined with various speeds for the asynchronous motor, and torque angles for the synchronous motor. For the 
asynchronous motor, efficiency is plotted versus speed (taking into consideration that $1355 \mathrm{rpm}$ is the rated load speed so for this speed the efficiency factor presented in Table 5 can be read). For the synchronous motor, efficiency is plotted versus torque angle, taking into consideration that at rated load, torque angle is $91.2^{\circ}$ so for this angle the presented efficiency in Table 5 can be read, as well.

Table 5 Comparison of performance characteristics

\begin{tabular}{|c|c|c|}
\hline \multicolumn{3}{|c|}{ Rated load operation } \\
\hline Parameter & AMAM & AMSM \\
\hline stator phase current $\mathrm{I}_{1}(\mathrm{~A})$ & 5.24 & 3.74 \\
\hline motor total weight $(\mathrm{kg})$ & 11.4 & 12.39 \\
\hline iron core losses $\mathrm{P}_{\mathrm{FE}}(\mathrm{W})$ & 27.7 & 6.91 \\
\hline stator winding copper losses $\mathrm{P}_{\text {cus }}(\mathrm{W})$ & 293.16 & 82.8 \\
\hline rotor winding copper losses $\mathrm{P}_{\text {cur }}(\mathrm{W})$ & 236 & 0 \\
\hline total losses $\mathrm{P}_{\text {loss }}(\mathrm{W})$ & 568.08 & 101.1 \\
\hline input power $\mathrm{P}_{1}(\mathrm{~kW})$ & 2.768 & 2.3 \\
\hline output power $\mathrm{P}_{2}(\mathrm{~kW})$ & 2.199 & 2.2 \\
\hline rated torque $\mathrm{T}_{\text {mech }}(\mathrm{Nm})$ & 15.5 & 14.09 \\
\hline efficiency $\eta(\%)$ & 79.4 & 95.6 \\
\hline power factor $\cos \varphi(/)$ & 0.802 & 0.933 \\
\hline torque angle $\left(^{\circ}\right)$ & / & 91.238 \\
\hline rated speed $\mathrm{n}_{\mathrm{n}}(\mathrm{rpm})$ & 1355 & 1500 \\
\hline \multicolumn{3}{|c|}{ No-load operation } \\
\hline no-load current $\mathrm{I}_{0}(\mathrm{~A})$ & 2.88 & 1.29 \\
\hline no-load input power $\mathrm{P}_{0}(\mathrm{~W})$ & 134.68 & 28.8 \\
\hline \multicolumn{3}{|c|}{ Locked rotor operation } \\
\hline starting torque $\mathrm{T}_{\text {start }}(\mathrm{Nm})$ & 35.26 & 59.43 \\
\hline
\end{tabular}

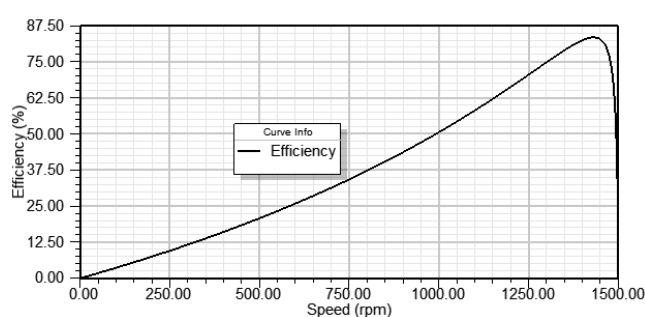

(a) AMAM

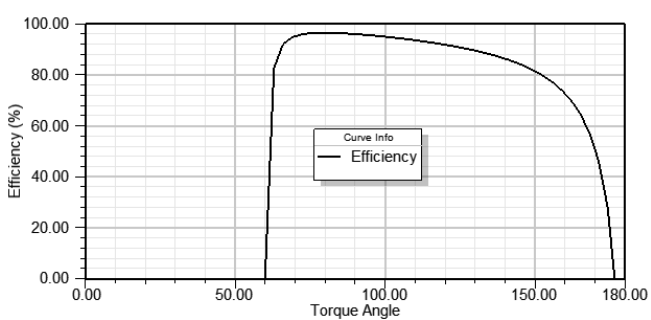

(b) AMSM

Fig. 7 Efficiency factor steady-state characteristics 
The mechanical torque is another important operating characteristic of the both types of the motors. Fig. 8 presents the torque of both motors. In case of the asynchronous motor, it is plotted for various motor speeds i.e. motor operating regimes. For the synchronous motor, all three types of torques that are present in the motor operation are presented in Fig. 8. The asynchronous torque that is produced by squirrel cage aluminum rotor winding, also known as damper winding, the breaking torque that is produced by permanent magnets and the resulting torque, which is the sum of the previous two, are presented in Fig. 8. The third key parameter in operation of the motors is the power factor. A low power factor causes a reduction in the electrical system distribution capacity by increasing the current amplitude and voltage drop. The LSSPMM operates with a higher power factor than the asynchronous motors. This is due to a reduction of a stator current because of the decreased magnetizing current. This is also the case with our analyzed synchronous motor, which at the rated load operation, has a considerably higher power factor than the asynchronous motor (Table 5). The power factor is plotted and presented in Fig. 9. For the asynchronous motor, it is plotted versus speed, and for the synchronous motor versus torque angle. For the rated speed i.e. motor angle, the rated power factor can be read.

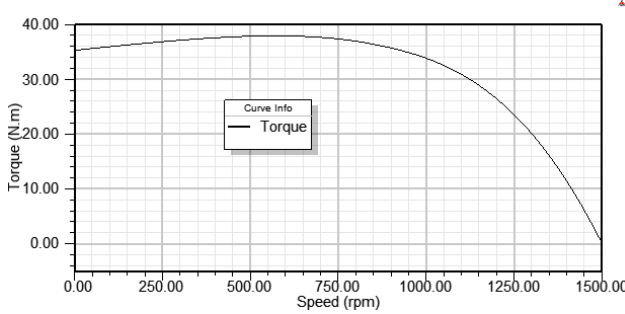

(a) AMAM

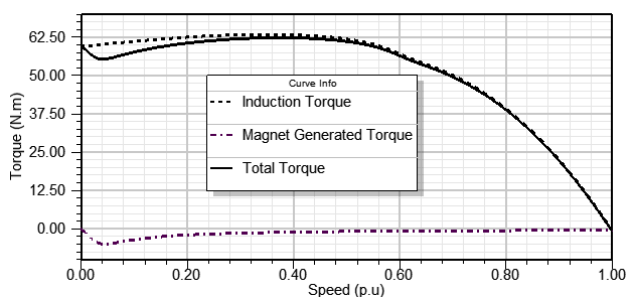

(b) AMSM

Fig. 8 Mechanical torque steady-state characteristics

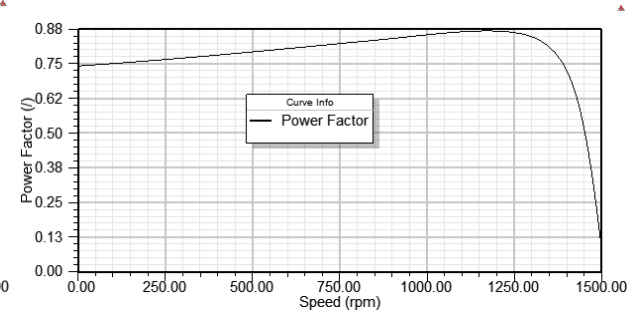

(a) AMAM

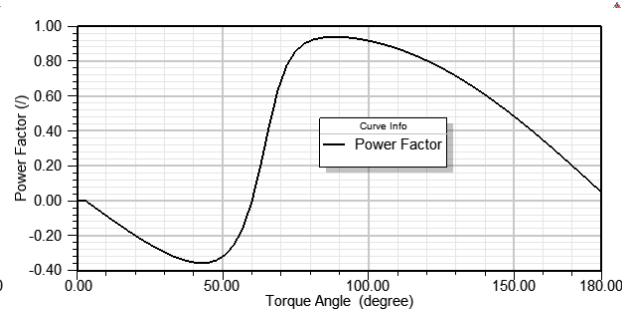

(b) AMSM

Fig. 9 Power factor steady-state characteristics

\subsection{Numerical models}

Numerical models are useful in obtaining the magnetic flux density in motor crosssection. The parts of the motor core where the high saturation exists can be easily detected and consequently the motor design can be modified in order to avoid forming of "weak" parts in the motor construction. Both analyzed motors are solved for the magnetic flux density by the aid of FEM and the obtained results are presented in Fig. 10. 


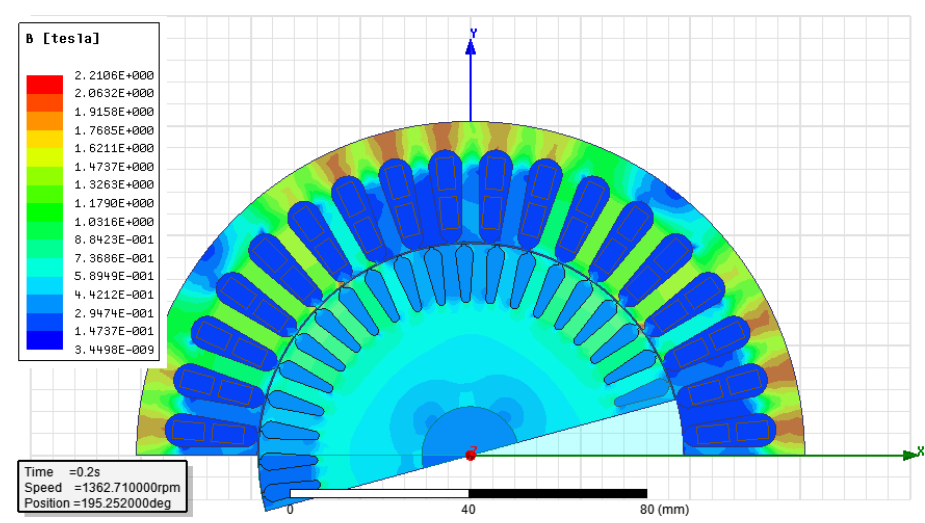

(a) AM

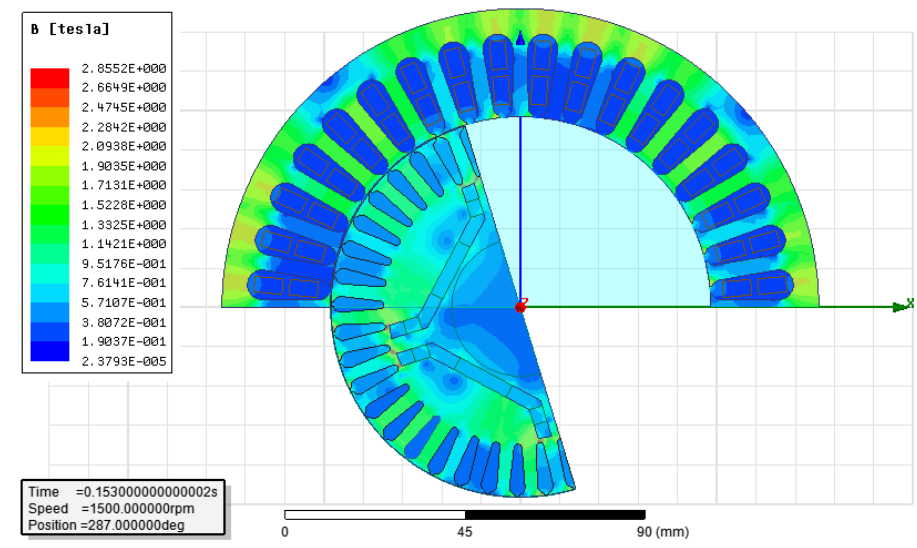

(b) LSSPMM

Fig.10 Magnetic flux density distribution

\subsection{Dynamic characteristics}

The analysis and comparison of both motors is completed with obtaining the dynamic characteristics of speed, torque and current when motors are fed by the three phase symmetrical voltage and are loaded with step load, $250 \mathrm{~ms}$ after the acceleration of the motor has finished. The obtained results of motor speed, torque and current are presented in Figs. 11, 12 and 13 respectively. The objective of this analysis is to validate the starting of LSSPMM as this type of motor may have difficulties during starting because of the breaking torque from the magnets or inability to reach the synchronous speed i.e. it cannot synchronize. Therefore, the acceleration of the synchronous motor with rated load to the synchronous speed is analyzed as well. An important part of the analysis for this type of the motor are the dynamic characteristics where can be analyzed motor starting i.e. the acceleration time, whether the synchronous speed is reached and how the motor responds to the sudden load changes. In addition, the dynamic behavior of the asynchronous motor can provide important data for operation of the motor. Similarly as the synchronous 
motor, the acceleration of the asynchronous motor up to the rated speed (in case when motor is loaded with rated load) can be analyzed as well. The obtained results from the dynamic models can be compared with the results from the analytical models for the purpose of their mutual validation.

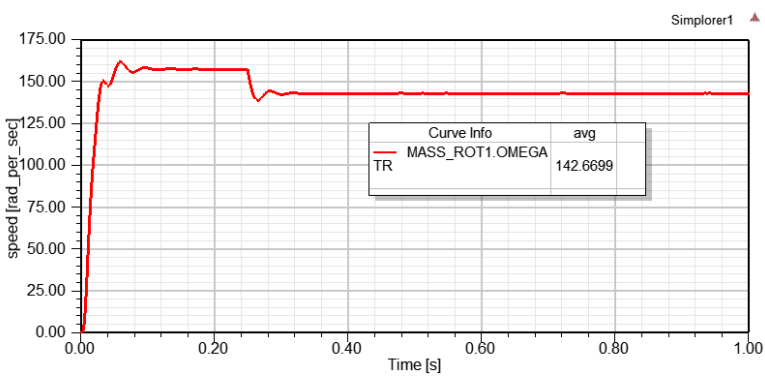

(a) AM

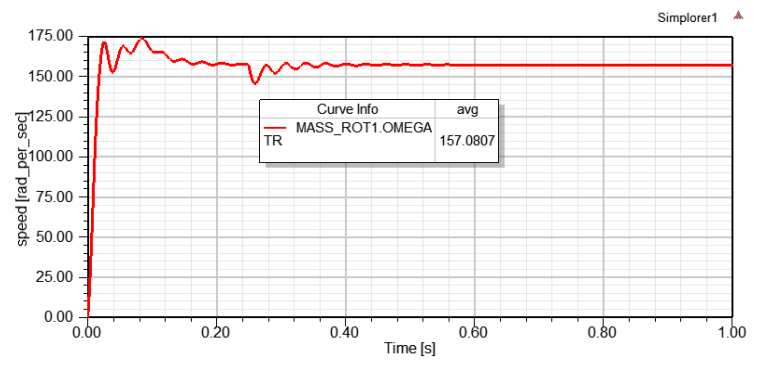

(b) LSSPMM with step load

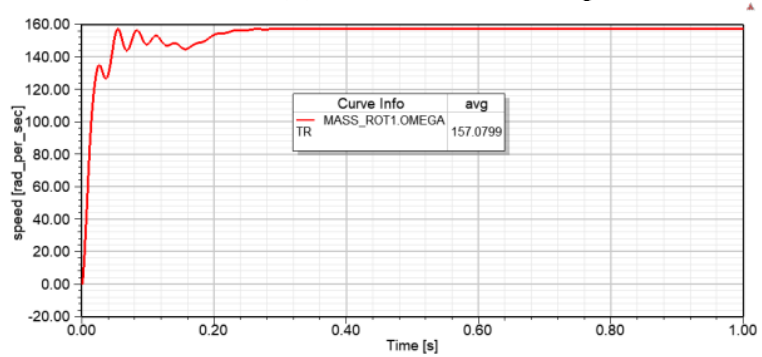

(c) LSSPMM with continuous load

Fig. 11 Transient characteristics of speed 


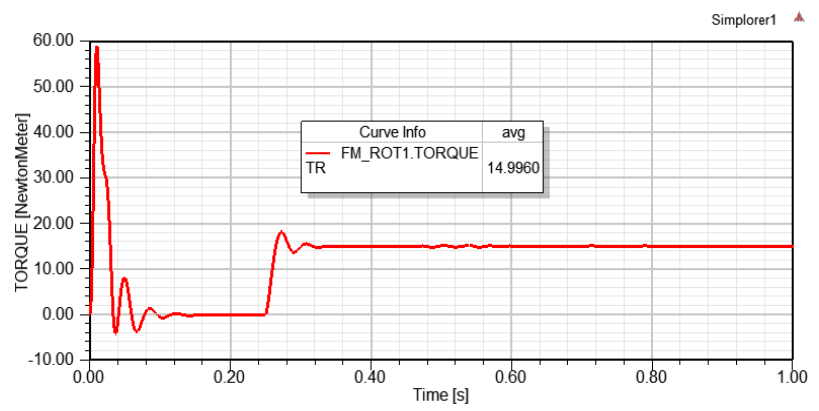

(a) $\mathrm{AM}$

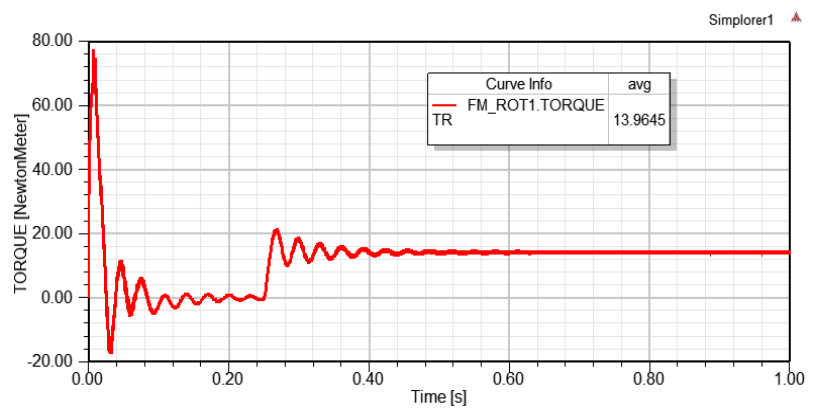

(b) LSSPMM with step load

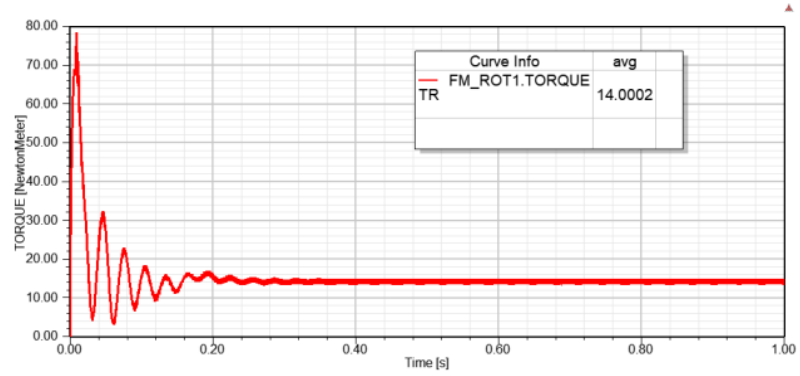

(c) LSSPMM with continous load

Fig. 12 Transient characteristics of torque 


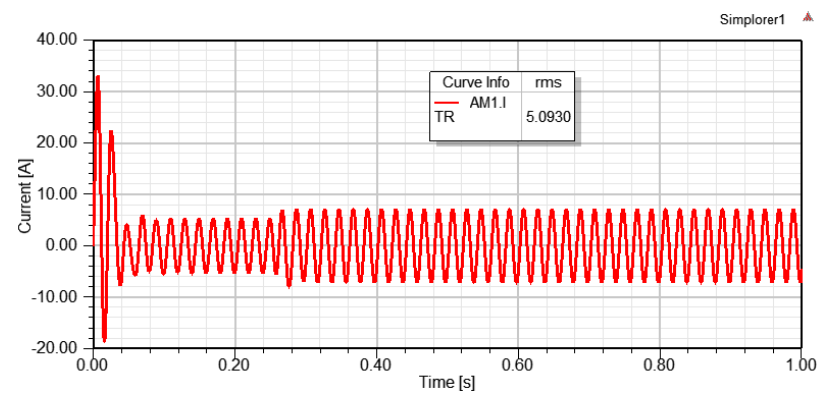

(a) AM

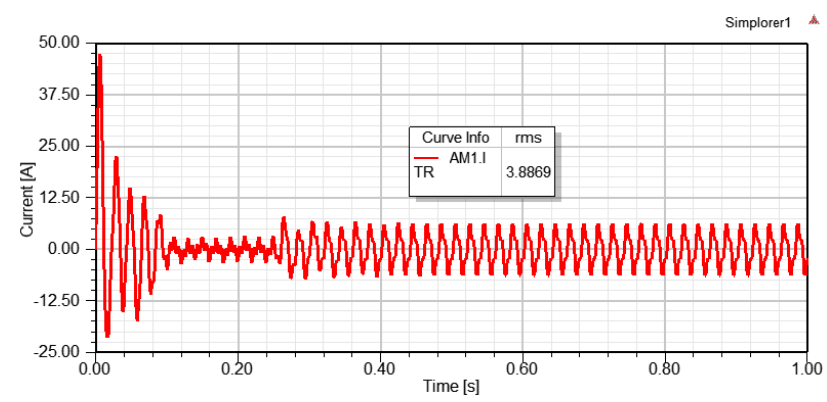

(b) LSSPMM with step load

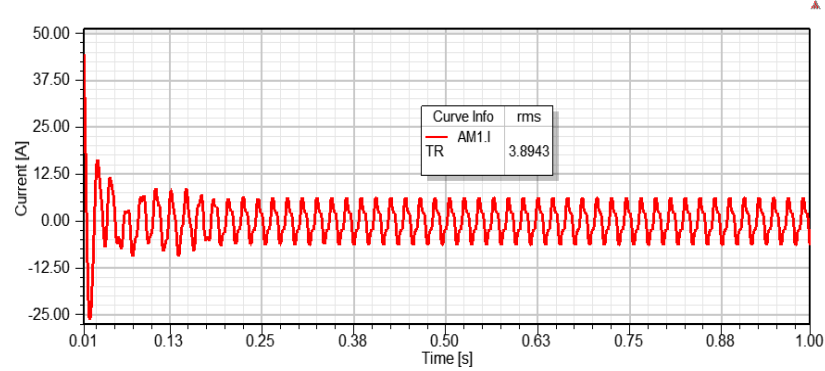

(c) LSSPMM with continius load

Fig. 13 Transient characteristics of current

\section{DisCUSSION OF THE RESULTS}

The increasing importance of the electricity savings has emphasized the need of more efficient electric motors. According to some studies, electric motors are responsible for about $45 \%$ of the total consumption of electric energy. A viable alternative to three-phase squirrel cage motors, which are the most often used motors in all industrial application, has become a main focus of many researchers and motor manufacturers, as the asynchronous motor is limited in improving the efficiency due to its construction and principle of operation. The current is induced in rotor, which is responsible for the copper losses in the 
rotor. In addition, the magnetizing current that is drawn from the network increases the total line current and consequently the stator copper losses. The most common range of efficiency for the small asynchronous induction motors up to $5 \mathrm{~kW}$ is between $85-89 \%$. A further increase of efficiency for this type of motors dramatically increases the price. Making them more efficient is a trade - off between costs, power and size. Some research has been done regarding the efficiency improvement at asynchronous motors for power ratings $3.5 \mathrm{~kW}$, $7 \mathrm{~kW}$ and $15 \mathrm{~kW}$ by using the copper cage winding instead of aluminum and low losses electrical steel. However, the premium steel and the copper rotor do not give rise of any further improvement (from EFF2) for the $3 \mathrm{~kW}$ and $7.5 \mathrm{~kW}$, while the $15 \mathrm{~kW}$ reaches the EFF1 class [31]. So even with high cost materials achieving the super-premium efficiency levels can be a challenging task for the asynchronous motors. Therefore, a viable alternative to the asynchronous motor in terms of increased efficiency should be considered within synchronous motors, known for the high efficiency. Two main modifications were derived in this paper in order to modify the three-phase squirrel cage motor into line- start three-phase permanent synchronous motor. Firstly, the rotor was redesigned by adding flux barriers and permanent magnets inside the barriers. Secondly, the diameter of the copper wire in threephase stator winding was modified, i.e. the cross-section was increased, and consequently the resistance was lowered (Table 4). The slot fill factor is increased, due to the increased wire diameter, to $69 \%$ at synchronous motor, but it is still well below the limited slot fill factor of $75 \%$ (Table 4). The reduced stator current and the stator winding resistance contributed to the lower copper losses. Lower copper losses in the line-start synchronous motor at steady-state operation are also attributed to the nullified copper losses in the squirrel cage winding. Almost $20 \%$ of losses in the asynchronous motors associate with rotor cage losses. In steady-state operation of the synchronous motor, meaning motor is operating with the synchronous speed, no current is induced in the rotor winding and consequently there are no copper losses in it. From the Table 5 it can be observed that the no-load current at LSSPMM is considerably lower than the no-load current of AM. The reason for this is that the magnets provide the magnetization in LSSPMM whereas the magnetization of the AM implies a magnetizing current in the stator winding. Consequently the power factor of the LSSPMM was increased, which increased the electrical system distribution capacity, i.e. the motor input power $\mathrm{P}_{1}$ was reduced, or consumption of electrical energy was reduced. The motor modification was performed with one constraint, the motor output power $\mathrm{P}_{2}$ should remain unchanged (Table 5). Therefore, in both motors the output mechanical power remains almost unchanged (Table 5). The total losses were lowered as well, which consequently increased the efficiency from $79.7 \%$ at asynchronous motor to $95.6 \%$ at synchronous. In most cases, standard asynchronous motors operate efficiently, with typical efficiency ranging between 80 and 93\%. Super premium efficiency motors perform significantly better. An efficiency gain of only $2 \%$, from $92 \%$ to $94 \%$, results in a $25 \%$ reduction of losses. Most of the motor losses result in heat emitted into the atmosphere. Reduced losses can significantly reduce cooling load in the industrial facility's cooling systems. As the synchronous motor operates with synchronous speed, which is bigger than the rated speed of the asynchronous motor, consequently the mechanical torque for the same output power is slightly reduced. Fig. 7 presents the efficiency factor of both motors, where can be read the efficiency at the rated speed, i.e. torque angle respectively. The presented results in Fig.7 support the data in Table 5. The same conclusion is valid for the Figure 9, where the power factor of both motors is presented. Again for the rated load operating point, 
the power factor of both motors can be read. The torque of the line-start synchronous motor is the sum of the breaking torque (produced by permanent magnets), and the asynchronous torque (produced by the squirrel cage winding). This is presented in Figure 8b. Generally, the line-start synchronous motors have good starting torque. However, for this type of the motors, the high load inertia, for example fans, can limit the synchronization capability of the motor. LSSPMM can start but it will not be able to run into synchronism and can stall before the synchronous speed. The proper dimensioning of rotor bars and the dimensions and quantity of permanent magnet material is of key importance for this type of the motors. It can be stated that an increase of the permanent magnet flux in the machine worsens the synchronization capabilities. On the other hand, the increase of permanent magnet material increases the efficiency and power factor in steady-state operation. The induction torque can be maximized near the synchronous speed in order to maximize the synchronization capability of the motor by lowering the cage resistance. On the other hand, the reduction of cage resistance reduces the starting torque of the motor. The modelled line-start synchronous motor is based on the same squirrel cage winding as it is in asynchronous motor. Motor is well designed regarding the squirrel cage winding and the permanent magnet material as it has sufficiently large starting torque and relatively low breaking torque (Table 5). A better overview of the dynamics of the motors, i.e. behaviour of the motors during starting and in steady-state operation (after the motor has accelerated up to the rated, i.e. synchronous speed) is illustrated in Figs. 11 and 12. In Fig. 11, both motors were accelerated at no load up to the steady-state operation with rated load, meaning for the asynchronous motor the rated speed of $142.66 \mathrm{rad} / \mathrm{s}$ or $1362 \mathrm{rpm}$ and for the synchronous motor up to the synchronous speed of $157.08 \mathrm{rad} / \mathrm{s}$ or $1500 \mathrm{rpm}$. Additionaly, the acceleration of the loaded synchronous motor is presented in Fig. $11 \mathrm{c}$ ). The synchronous motor is accelerated up to the synchronous speed with the rated load. This can be effected due to the large starting torque of the motor. Synchronization is sucesfully achieved. Here should be noted that obtained results from the dynamic models are in very good agreement with the obtained results from the analytical models (Table 5) i.e. rated speed of $1355 \mathrm{rpm}$ in the analytical model and $1362 \mathrm{rpm}$ in the dynamic model of the asynchronous motor. Synchronous motor in both models (analytical and dynamic) operates with a constant synchronous speed of $1500 \mathrm{rpm}$. The overall comparison of the results obtained from the analytical and the dynamic models is presented in Table 6 . The rated load operating condition is obtained by loading both motors with step load, two hundred and fifty milliseconds after the motors were accelerated. The moment when the motors were loaded can be clearly observed in the dynamic characteristic of torque, presented in Fig. 12. After the motor had accelerated, the torque decreased to the no-load torque, which is a very low value, up to the moment when the step load is applied the shaft, equal to the rated torque, and consequently the torque of the motors increases up to the rated torque. For the acceleration with the rated load, after the motor has reached the synchronous speed, the torque reached the value of the rated torque. Again, the comparison between obtained results of the torque from the analytical and the dynamic models is presented in Table 6. A similar behaviour is observed in transient characteristics of the current (Fig. 13), where the current in both motor models, reaches the steady state value, at the rated load, of 5.09 A for the asynchronous and 3.89 A for the synchronous motor. The obtained results of the current from the dynamic models are in very good agreement with the obtained currents from the analytical models i.e. 5.24 A and 3.74 A respectively (Table 5). After the accelerations of the motors have finished, the current decreases to the no-load 
current (acceleartion without load), until the moment when the step load is applied. At that moment, the current increases up the rated current, due to the applied rated load (Fig. 13). For the acceleration with the rated load in case of the synchronous motor, after the acceleration has finished, and the motor reaches the synchronous speed and stable operation, the current reaches the value of the rated current $(3.89 \mathrm{~A})$, which can be expected for this operating regime. In Fig 13 b) and Fig 13 c) a distortion of the current waveforms at synchronous motor due to the presence of higher order harmonic can be observed. The presence of harmonics in currents and torque due to the flux from the permanent magnets is one of the major drawbacks of this type of the motor. The harmonics contribute also to the higher noise during the motor operation. The problem of the harmonics at line-start synchronous motor has been analyzed and adequate solution has been proposed by modifying rotor teeth width [32]-[33]. The presence of the harmonics is more pronounced with the increase of the load [32]. Their presence at the line-start synchronous motor can be also observed in the waveform of the air gap flux density, which usually for this type of the motor has a rectangular form. To overcome this negative effect in the operation of the linestart synchronous motor some authors propose the usage of filter that significantly reduces the THD [34].

Table 6 Comparison of results from analytical and dynamic models

\begin{tabular}{lcccc}
\hline & \multicolumn{2}{c}{ Analytical model } & \multicolumn{2}{c}{ Dynamic model } \\
\cline { 2 - 5 } & Synch. & Synch. & Asynch. & Synch. \\
\hline rated phase current (A) & 5.24 & 3.74 & 5.09 & 3.89 \\
rated speed (rpm) & 1355 & 1500 & 1362 & 1500 \\
rated torque (Nm) & 15.5 & 14.09 & 14.99 & 13.96 \\
\hline
\end{tabular}

From the presented dynamic characteristics of the line-start synchronous motor it can be concluded that motor accelerates and reaches the synchronous speed i.e. for the presented example of the step load and continuous rated load, it operates with synchronous speed without losing the synchronism. In transient regimes (start up and near to the steady state operating point), the operation of the asynchronous motor is more stable with very small oscillations in the transient characteristic during acceleration and when motor reaches the steady-state operating point. The acceleration time of both motors is almost the same. Linestart synchronous motors should work and they have advantages in applications involving frequent start and stops because permanent magnet motors have low inertia. The magnetic flux density distribution in the cross-sections of the motors verifies the proper design of the motors. In case of the synchronous motor, the points of high flux density are detected near the sharp edges of the flux barriers. The motor uses Samarium Cobalt magnets, which are known as strong rare earth magnets, generally ranked similarly in strength, to neodymium magnets. In the future research redesigning and improvement of the rotor configuration should be considered, in order to lower the flux density in critical parts. This could be a challenging task considering that motor operating characteristics should remain the same or even improved. One of the advantages of line-start synchronous motors is that they come in the same frame size as conventional asynchronous motors for the same motor power rating. This makes them an attractive replacement of the conventional standard efficiency asynchronous motors. The line-start, without the need of controller or feedback device, makes their operation easy and cost efficient. 


\section{CONCLUSION}

The synchronous motors have been studied as a viable alternative to the asynchronous motors due to high efficiency and high power factor. Permanent magnet synchronous motors can have larger air gaps without affecting the efficiency. With larger air gap, the required amount of magnet material increases, so the associated cost. In addition, line-start synchronous motors have overcome the difficulties of the synchronous motors, regarding starting and the need of voltage inverters for that purpose. They can be directly started when fed with the network voltage. The paper presents the modification of the three-phase asynchronous motor in the line-start synchronous motor with minimum interventions in the motor design. The motor outer dimensions remain unchanged, the rotor is redesigned, and the diameter of the stator wire is increased while the motor output power remains the same as at the asynchronous motor. The applied modifications resulted in efficiency increase from $79.7 \%$ to $95.6 \%$. The power factor is also considerably improved from 0.8 to 0.93 . The motor line current is decreased as well as the no-load current. Beside analytical calculations, which were done in the module of the software Ansys Electronics Desctop for analytical calculation of motor parameters and steady-state characteristics, numerical models of the motors were derived as well. They allow the magnetic flux density in the cross-section of the motors to be calculated. These models detected the points of high saturation of the magnetic core near the edges of the flux barriers in the rotor of the synchronous motor. The further research should be focused on improving the rotor design in order for this saturation of the rotor core to be avoided. Dynamic models for obtaining the transient characteristics of the motors at starting and acceleration up to the rated speed were also derived. Both motors were accelerated at no load and step load was applied to the rotor shaft two hundred fifty milliseconds after the acceleration had finished. Additionally, acceleration of the loaded linestart synchronous motor was analyzed as well. The line-start synchronous motor accelerated and reached synchronous speed when fed by the network voltage. In addition, it operated with the rated load applied on the motor shaft, after the acceleration had finished, without losing the synchronism. The paper should outline the design possibilities for redesigning the asynchronous squirrel cage motor in the line-start synchronous motor for the same output power and with minimal consumption of permanent magnet material. The up to now research on the design of the line-start synchronous motor shows promising results. However, the line-start synchronous motor is not the ideal replacement of the asynchronous motor. There is a number of manufacturing difficulties that should be overcome. The design of the rotor is more complicated, compared to the squirrel cage motor, manufacturing costs are higher; the price of the magnets increases the cost of the synchronous motor. Therefore, again, the focus of the further research will be on combining the good features of the asynchronous and the synchronous motors in the line-start synchronous reluctance motor, which is magnet free. The design of the flux barriers, without magnets, combined with the adequate design of the squirrel cage winding for achieving good starting and steady-state operating characteristics will be a challenging task. 


\section{REFERENCES}

[1] H. Qiu, Y. Zhang, K. Hu, C. Yang and R. Yi " The influence of Stator Winding Turns on the SteadyState Performance of Line-Start Permanent Magnet Synchronous Motors," Energies, vol. 12 , 2363, pp. 1-15, 2019. [Online]. Available: https://doi.org/10.3390/en12122363

[2] M.Tian, X. Wang, D. Wang, W. Zhao, C. Li, "A Novel Line-Start Permanent Magnet Synchronous Motor with 6/8 Pole Changing Stator Winding," IEEE Transactions on Energy Conversion, vol. 33, no. 3, pp.1164 - 1174, 2018. [Online]. Available: https://doi.org/10.1109/TEC.2018.2826550

[3] H. Qui, K. Hu, R. Yi, Y. Wei, " Influence of voltage unbalance on the steady-state performance of online start permanent magnet synchronous motor," IEEJ Transaction on Electrical and Electronic Engineering, vol.14, no.11, pp. 1673-1680, 2019. [Online]. Available: https://doi.org/10.1002/tee.22990

[4] B. Zöhra, M. Akar, M. Eker, "Design of a Novel Line Start Synchronous Motor Rotor," Electronics, vol. 8, no.25, pp. 1-18, 2019 . [Online]. Available: https://doi.org/10.3390/electronics8010025

[5] X. Xu, Y. Cui, X. Wang, H. Feng, J. Si, "Performance of Line-Start Permanent Magnet Synchronous Motor with Novel Rotor Structure," International Journal of Digital Content Technology and its Applications, vol.7, no. 6, pp. 1217-1225, 2013. doi:10.4156/jdcta.vol7.issue6.139

[6] C. Ogbuka, C. Nwosu, M. Agu, "Dynamic and steady-state comparison of line-start permanent magnet synchronous motors with interior and surface magnets," Archives of Electrical Engineering, vol. 65, no.1, pp. 105-116, 2016. [Online]. Available: http://dx.doi.org/10.1515/aee-2016-0008

[7] X.Y. Ma, G-J. Li, Z-Q. Zhu, G.W. Jewell, J. Green, "Investigations on Synchronous Reluctance Machines with Different Rotor Topologies and Winding Configurations," IET Electric Power Applications, vol. 12, no. 1, pp. 45-53, 2018. [Online]. Available: http://dx.doi.org/10.1049/iet-epa.2017.0199

[8] P. Hudák, V. Hrabovcová, "Mathematical modelling and parameter determination of reluctance synchronous motor with squirrel cage," Journal of Electrical Engineering, vol. 61, no. 6, pp. 357-364, 2010. [Online]. Available: https://doi.org/10.2478/v10187-010-0055-y

[9] P. Sekerák, V. Hrabovcová, J. Pyrhönen, L. Kalamen, P. Rafajdus, M. Onufer ,"Ferrites and different winding types in permanent magnet synchronous motor," Journal of Electrical Engineering, vol. 63, no. 3, pp. 162-170, 2012. [Online]. Available: https://doi.org/10.2478/v10187-012-0024-8

[10] A.H. Isfahani, S. Vaez-Zadeh, "Line start permanent magnet synchronous motors: Challenges and opportunities," Energy, vol. 34, no. 11, pp. 1755-1763, 2009. [Online]. Available: https://doi.org/10. 1016/j.energy.2009.04.022

[11] H. Behbahanifard, A. Sadoughi, "Cogging Torque Reduction in Line Start Permanent Magnet Synchronous Motor,” Journal Electrical Engineering and Technology, vol. 11, no. 4, pp. 878-888, 2016. [Online]. Available: https://doi.org/10.5370/jeet.2016.11.4.878.

[12] M.N.F Ibrahim, P. Sergeant, E. Rashad, "Simple Design Approach for Low Torque Ripple and High Output Torque Synchronous Reluctance Motor,' Energies, vol. 9, 942, pp. 1-14, 2016. [Online]. Available: https://doi.org/10.3390/en9110942

[13] L. Jing, J. Gong, Y. Lin, "Analysis and Reduction of Cogging Torque of Line-Start Permanent Magnet Motors," Progress In Electromagnetics Research M, vol. 78, pp. 115-124, 2019. [Online]. Available: https://dx.doi.org/ 10.2528/PIERM18120902

[14] A.H. Isfahani, S. Vaez-Zadeh, "Effects of Magnetizing Inductance on Start-Up and Synchronization of Line-Stat Permanent-Magnet Synchronous Motors," IEEE Transactions on Magnetics, vol. 47, no. 4, pp. 823- 829, 2011. [Online]. Available: https://doi.org/10.1109/TMAG.2010.2091651

[15] M.A. Rahman, A.M. Osheiba, K. Kurihara, M.A. Jabbar, H. W. Ping, K. Wang, H.M. Zubayer, "Advances on Single-Phase Line-Start High Efficiency Interior Permanent Magnet Motor," IEEE Transactions on Industrial Electronics, vol. 59, no.3, pp. 1333-1345, 2012. [Online]. Available: https://doi.org/10.1109/TIE.2011.2167111

[16] M. Gwoździewicz, J. Zawilak, "Single-Phase Line Start Permanent Magnet Synchronous Motor with Skewed Stator," Power Electronics and Drives, vol. 1 (36), no. 2, pp. 187-194, 2016. [Online]. Available: https://doi.org/ $10.5277 /$ ped 160212

[17] M. Gedikpinar, Ö, Aydoğmuş, "Design of a self-starting hybrid permanent magnet hysteresis synchronous motor connected directly to the grid," Turkish Journal of Electrical Engineering \& Computer Sciences, vol. 25, no. 3, pp. 1657-1668, 2017. [Online]. Available: https://doi.org/10.3906/elk-1603-198

[18] P.R. Viego, V. Sousa, J.R. Gómez, E.C Quispe, "Direct on-line-start permanent-magnet-assisted synchronous reluctance motors with ferrite magnets for driving constant load," International Journal of Electrical and Computer Engineering, vol. 10, no. 1, pp. 651-659, 2020. [Online]. Available: http://doi.org/10.11591/ ijece.v10i1.pp651-659 
[19] M. Karami, N. Mariun, M.R. Mehrjou, M. Z. A. A. Kadir, N. Misron, M. A. M. Radzi "Static Eccentricity Fault Recognition in Three-Phase Line Start Permanent Magnet Synchronous Motor Using Finite Element Method," Mathematical Problems in Engineering, vol. 2014, pp. 1-12, 2014. [Online]. Available: https://doi.org/10.1155/2014/132647

[20] I. Hussein, Z. Al-Hamouz, M.A. Abido, A. Milhem, "On the Mathematical Modelling of Line-Start Permanent Magnet Synchronous Motors under Static Eccentricity,” Energies, vol. 11, pp. 1-17, 2018. [Online]. Available: https://doi.org/10.3390/en11010197

[21] K.I. Baradieh, Z. Al-Hamouz, "Modelling and Simulation of Line Start Permanent Magnet Synchronous Motor with Broken Bars," Journal of Electrical \& Electronic Systems, vol. 7, no.2, pp. 1-7, 2017. [Online]. Available: http://dx.doi.org/10.4172/2332-0796.1000259

[22] F. Ismagilov, V. Vavilov, R. Urazbakhtin , "Optimization of Synchronous Electric Motors with Asynchronous Start by Genetic Algorithms,” International Review of Aerospace Engineering, vol. 11 no. 2, pp. 66-75, 2018. [Online]. Available: https://doi.org/10.15866/irease.v11i2.13365

[23] Ł. Knypiński, "Optimal design of the rotor geometry of line-start permanent magnet synchronous motor using the bat algorithm,” Open Physics., vol. 15, no.1, pp. 965-970, 2017. [Online]. Available: https://doi.org/ 10.1515/phys-2017-0119

[24] V. Sarac, D. Iliev, "Synchronous Motor of Permanent Magnet compared to Asynchronous Induction Motor," Electrotehnica, Electronica, Automatica (EEA), vol. 65, no. 4, pp. 51-58, 2017. [Online]. Available: http://www.eea-journal.ro/ro/d/5/p/EEA65_4_8

[25] Y. Duan "Method for Design and Optimization of Surface Mount Permanent Magnet Machines and Induction Machines", Dissertation, Georgia Institute of Technology, 2010. [Online]. Available: https://smartech.gatech.edu/bitstream/handle/1853/37280/duan_yao_201012_phd.pdf

[26] A. A. Adam, K. Gülez, S. Köroğlu, "Stray magnetic field distributed around a PMSM", Turkish Journal of Electrical Engineering \& Computer Sciences, vol. 19, no.1, pp. 119-131, 2011. [Online]. Available: http://dx.doi.org/10.3906/elk-1003-404

[27] J. Soleimani, A. Vahedi, A. Ejlali, M. B. Bafghi "Study on interior permanent magnet synchronous motors for hybrid electric vehicle traction drive application considering permanent magnet type and temperature,' Turkish Journal of Electrical Engineering \& Computer Sciences, vol. 22, no.6, pp. 15171527, 2014. [Online]. Available: https://doi.org/10.3906/elk-1105-58

[28] M. Güleç, E. Yolaçan, Y. Demir, O. Ocak, M. Aydin, "Modelling based on 3D finite element analysis and experimental study of a 24-slot 8-pole axial-flux permanent-synchronous motor for no cogging torque and sinusoidal back-EMF," Turkish Journal of Electrical Engineering \& Computer Sciences, vol. 24, no. 1, pp. 262-275, 2016. [Online]. Available: https://doi.org/10.3906/elk-1308-150

[29] A.S.O. Ogunjuyigbe, A.A. Jimoh, T.R. Ayodele, "Dynamic and transient behavior of a line start, capacitance compensated synchronous reluctance machine," Journal of Electrical Systems and Information Technology, vol. 5, no. 3, pp. 843-860, 2018. [Online]. Available: https://doi.org/10.1016/j.jesit.2016.12.012

[30] J. C. Asogwa, E. S. Obe, "Investigation of the Transient and Steady-State Operations of Two Line Start Permanent Magnet Motors (LSPMMS) with Different Rotor Configurations," Nigerian Journal of Technology (NIJOTECH), vol 38, no. 1, pp. 185-192, 2019. [Online]. Available: http://dx.doi.org/10.4314/njt.v38i1.23

[31] F. Parasiliti, M. Villani, C. Paris, O. Walti, G. Songini, A. Novello, T. Rossi, "Three-phase induction motor efficiency improvement with die-cast copper rotor cage and premium steel," in Proceedings of Symposium on Power Electronics, Electrical Drives, Automation \& Motion : SPEEDAM 2004, Italy, pp. 338-343, 2004. [Online]. Available: https://www.copper.org/environment/sustainable-energy/electricmotors/education/motor-rotor/pdf/Three-Phase_Induction.pdf

[32] T. Zawilak, J. Zawilak, “ Minimization of Higher Harmonics in Line-Start Permanent Magnet Synchronous Motor”, Prace Naukowe Instytutu Maszyn, Napędów i Pomiarów Elektrycznych Politechniki Wrocławskiej Studia i Materiały, vol 63, no. 29, pp. 107-115, 2009 . [Online]. Available: http://yadda.icm.edu.pl/yadda/ element/bwmeta1.element.baztech-article-BPW9-0009-0014

[33] M. Gwoździewicz, L. Antal, "Investigation of Line Start Permanent Magnet Synchronous Motor and Induction Motor Properties”, Prace Naukowe Instytutu Maszyn, Napędów i Pomiarów Elektrycznych Politechniki Wrocławskiej Studia i Materiały, vol 64, no. 30, pp. 13-20, 2010 . [Online]. Available: http://yadda.icm.edu.pl/yadda/element/bwmeta1.element.baztech-article-BPW6-0021-0014

[34] G. S. Chingale, R. T. Ugale, "Harmonic Filter Design for Line Start Permanent Magnet Synchronous Motor", in Proceedings of International Conference on Advances in Electrical Engineering (ICAEE), India, 2014. [Online]. Available: https://doi.org/10.1109/ICAEE.2014.6838503 